\title{
Sri Lanka Journals Online (SLJOL): Ten years of success
}

\author{
Jithangi Wanigasinghe \\ Editor of Ceylon Journal of Medical Science \\ Faculty of Medicine, University of Colombo, Sri Lanka
}

Before 2008, local research received little local and international visibility. The local publishing industry faced difficulties such as infrequency of publications, less visibility, less usability of local literature and limited circulation. Only a limited number of local journals maintained regular publications. The nonavailability of commercial publication services and the non-profit making nature of these publications compelled most local journals to be low profile.

It was in August 2008 that the Sri Lanka Journals Online (SLJOL), Sri Lanka's primary web-based journal platform, was initiated. It was established under a programme named PERI (Programme for the Enhancement of Research Information) which then became SRKS (Strengthening Research and Knowledge Systems) managed by the International Network for the Availability of Scientific Publications (INASP), United Kingdom.

SLJOL is a programme for online publishing of peerreviewed scholarly Sri Lankan journals which have an established track record (of at least two years). Its main objectives are to provide visibility to the scholarly content of Sri Lankan journals both locally and internationally and to help the journals to improve their publishing practices.

At its inception in 2008, there were only six journals as the Sri Lanka component of the Journals Online (JOL) project. Over just 10 years it has increased to more than 76 journals. It functions as a database of all journals published in Sri Lanka which covers a full range of academic disciplines such as agriculture, architecture building and planning, biological sciences, education,

\section{Author responsible for correspondence: \\ Jithangi Wanigasinghe \\ MBBS, DCH, MD (Paed Neurology), MPhil \\ Senior Lecturer in Paediatrics, Specialist in Paediatric \\ Neurology and Editor of Ceylon Journal of Medical Science \\ Faculty of Medicine, University of Colombo, Sri Lanka}

DOI: http://doi.org/10.4038/cjms.v54i2.4926

http://orcid.org/0000-0002-9413-8363 environmental sciences, law, mathematics and computer sciences, medicine, dentistry and allied health sciences, multidisciplinary sciences, physical sciences and social sciences.

SLJOL uses the open-source software, Open Journals System (OJS), created by the Public Knowledge Project (PKP) based in Canada. This software allows the journal content listed on SLJOL to be indexed through Open Archives Initiative search engines dedicated to research, which harvest the metadata for each journal article, making this work readily available to a global audience. Since 2015, the hosting of SLJOL website has been transferred to Ubiquity Press (UP), UK, with a major site upgrade, enhancing social media functionality.

Apart from hosting Tables of Content and full-text articles, SLJOL also provides a platform for the submission of articles as well as a facility to publish local journals online. It allows editors to carry out editorial processes such as peer-reviewing, editing, proofing and printing online. Other services provided include a home page for each journal, a sophisticated search tool, an email alert service and reference management.

In 2016, the Journal Publishing Practices and Standards (JPPS) framework which contains internationally recognized high standards of publishing and editorial best practices was introduced to the journals in SLJOL. All journals covered by SLJOL were assessed by INASP against a detailed and transparent set of JPPS criteria, ranking them into six (06) categories.

It allows the journals to apply for reassessment with evidence supporting improvement to obtain a higher JPPS rank. The most recent of these updates was issued at end of 2017.

Initially with the University of Colombo but later with the National Science Foundation (NSF) a Memorandum of Understanding was signed by INASP to facilitate a gradual transfer of the responsibility of management of the SLJOL website and the database. 
Since 2013, INASP with continued monitoring initiated this gradual transfer of responsibility to the National Science Library and Resource Centre (NSLRC) of the NSF. Since then, NSF has played the key role in its management as well as an enhancing role to support the local journals. From March 2018, the total administrative responsibility of managing SLJOL will be shouldered by the NSF. In the past 10 years, SLJOL has expanded to more than 76 Sri Lankan Journals hosting 9,220 research articles.

In $2017,165,438(68.2 \%)$ new visitors and 77,234 $(31.8 \%)$ returning visitors have been recorded and 78,774 full-text articles covered by the SLJOL have been downloaded globally.
The success of SLJOL can be attributed to the continued efforts by both INASP and the library staff of NSF. The contribution made by Ms. Sioux Cumming, Programme Manager JOL Project is specially noted. We wish the NSF, who will be taking over the complete managerial and administrative responsibility of SLJOL from March 2018, good luck and continued success.

\section{Acknowledgements}

I thank the NSF and INASP in providing information sources and statistics. 